TITLE:

\title{
Divergent and Chemoselective Transformations of Thioamides with Designed Carbene Equivalents
}

\section{$\operatorname{AUTHOR}(S)$ :}

Saito, Masato; Kobayashi, Yusuke; Takemoto, Yoshiji

\section{CITATION:}

Saito, Masato ... [et al]. Divergent and Chemoselective Transformations of Thioamides with Designed Carbene Equivalents. Chemistry - A European Journal 2019

\section{ISSUE DATE:}

2019-08-06

URL:

http://hdl.handle.net/2433/243264

\section{RIGHT:}

This is the peer reviewed version of the following article: [Masato Saito, Yusuke Kobayashi, Yoshiii Takemoto. Divergent and Chemoselective Transformations of Thioamides with Designed Carbene Equivalents. Chemistry - A European, 25(44), 10314-10318], which has been published in final form at https://doi.org/10.1002/chem.201902699. This article may be used for non-commercial purposes in accordance with Wiley Terms and Conditions for Use of Self-Archived Versions.: The full-text file will be made open to the public on 05 August 2020 in accordance with publisher's 'Terms and Conditions for Self-Archiving', この論文は出版社版でありません。引用の際には出版社版をご確認ご利用ください。; This is not the published version. Please cite only the published version. 


\title{
Divergent and chemoselective transformations of thioamides with designed carbene equivalents
}

\author{
Masato Saito, ${ }^{[a]}$ Yusuke Kobayashi, ${ }^{[a]}$ Yoshiji Takemoto*[a]
}

\begin{abstract}
The reactions of thioamides with ortho-nitro-substituted iodonium ylides proceeded under mild conditions to give enaminones or thiazoles, depending on the iodonium ylide used. This protocol allowed the use of protic solvents, including aqueous solutions, and therefore coupling reactions with complex molecules such as peptides or steroids were possible. A mild and efficient method for the synthesis of various iodonium ylides was established. A DFT calculation suggested that halogen bonding between a thioamide and iodonium ylide was important in this chemoselective coupling reaction. The potential use of enaminones conjugated with pharmaceuticals as prodrugs was also demonstrated.
\end{abstract}

Thioamides have attracted much attention because they are isosteres of amides, but with higher lipophilicities and stabilities. Many studies of peptides and proteins with thioamide moieties have been conducted. ${ }^{[1]}$ An increasing number of methods for the introduction of thioamides at desired positions of peptides are being developed. ${ }^{[2]}$ In addition, thioamides have high nucleophilicities and their selective transformations have recently been studied. ${ }^{[3]}$ In particular, the reactions of thioamide groups, which are rarely found in biomolecules, have potential applications in chemoselective bioconjugation, which is one of the most important tools for drug discovery and in chemical biology. ${ }^{[4,5]}$ However, only a few examples of such reactions have been reported. These reports include transition-metalcatalyzed coupling reactions with carbene equivalents. ${ }^{[5]}$ Use of diazomalonates as carbene precursors gave enaminones (Scheme $1 \mathrm{~A}$, eq. 1), ${ }^{[5 \mathrm{~d}-\mathrm{f}]}$ whereas thiazoles were obtained when $\alpha$-diazo ketoesters were used as the carbene precursors (Scheme 1A, eq. 2). ${ }^{[5 b, c]}$ Both products were supposedly obtained through $\mathrm{C}-\mathrm{S}$ bond formation. Although enaminones ${ }^{\left[{ }^{[6]}\right.}$ and thiazoles ${ }^{[7]}$ are both attractive pharmacophores with specific properties, these reactions generally require high temperatures because of the formation of inert complexes through thioamide coordination to the metal catalyst. It is therefore difficult to apply these reactions to heat-labile molecules such as proteins. Undesired $\mathrm{O}-\mathrm{H}$ insertion ${ }^{[8]}$ of metal carbenoids into polar solvents such as alcohols also prevents thioamide use with complex molecules, which are difficult to dissolve in non-polar solvents.

Herein, we report a highly chemoselective coupling reaction of various thioamides with a variety of carbene equivalents in protic solvent under mild conditions. We therefore focused on iodonium ylides (Scheme $1 \mathrm{~A}$, eqs. 3,4 ) as carbene equivalents ${ }^{\left[{ }^{[9]}\right.}$

[a] Masato, Saito, Dr. Yusuke Kobayashi, Prof. Dr. Yoshiji Takemoto Graduate School of Pharmaceutical Sciences, Kyoto University 46-29 Shimoadachi-cho, Yoshida, Sakyo-ku, Kyoto 606-8501, Japan

E-mail:Takemoto@pharm.kyoto-u.ac.jp

Supporting information for this article is given via a link at the end of the document. because hypervalent iodine compounds, including iodonium ylides, have recently been reported to have $\sigma$-holes, ${ }^{[10]}$ and they are expected to form halogen bonds $(X B)^{[11,12]}$ selectively with soft Lewis bases ${ }^{[13]}$ such as thioamides, even in the presence of a polar functional group such as an alcohol. However, the use of iodonium ylides as electrophiles (Scheme $1 \mathrm{~A}$, eq. 4) has been less studied ${ }^{[14,15]}$ than metal carbenoid precursors (Scheme $1 \mathrm{~A}$, eq. 3). This limitation is because of the poor solubility and instability of iodonium ylides, and side reactions such as nucleophile dimerization (Scheme $1 \mathrm{~A}$, eq. 5). The strongly basic conditions needed for their preparation ${ }^{[9 b, 16]}$ also hinders the synthesis of a range of iodonium ylides.

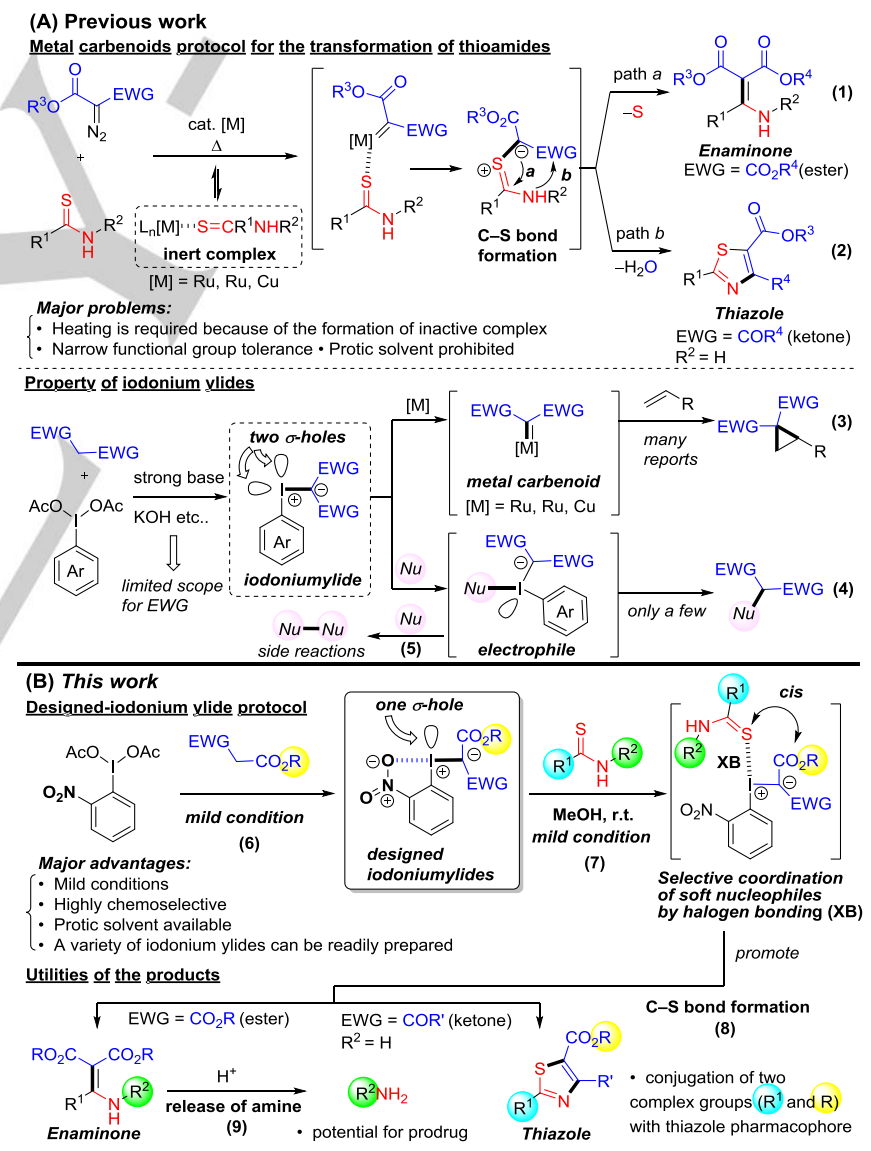

Scheme 1. Summary of this work

To solve these problems, we focused on the effects of ortho substituents on the solubility and stability of iodonium ylides $^{[14 b, 17]}$ and hypervalent iodine compounds. ${ }^{[18]}$ We envisaged that introduction of an ortho substituent would decrease side reactions by blocking one of the $\sigma$-holes, and cisselective coordination of thioamide to iodonium ylide would 
promote C-S bond formation (Scheme 1B, eqs. 7,8). In particular, the introduction of an ortho nitro group would enhance the reactivity of the corresponding precursor, $\operatorname{Arl}(\mathrm{III})(\mathrm{OAc})_{2}$, which would enable condensations with various active methylene compounds under mild conditions to produce iodonium ylides with broad functional group tolerance (Scheme 1B, eq.6). We also envisioned the application of the method to enaminone-based prodrug (Scheme 1B, eq. 9) and thiazoletethered conjugation of two complex molecules.

Table 1. Optimization of reaction conditions for chemoselective transformation of thioamides.

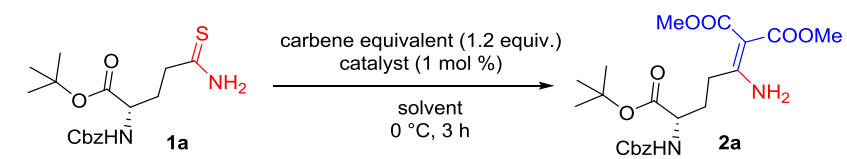

\begin{tabular}{|c|c|c|c|c|}
\hline Entry & $\begin{array}{c}\text { Carbene } \\
\text { equivalent }\end{array}$ & Catalyst & Solvent & Yield $(\%)^{[\mathrm{a}]}$ \\
\hline 1 & 3 & $\mathrm{Rh}_{2}(\mathrm{OAc})_{4}$ & $\mathrm{CH}_{3} \mathrm{OH}$ & N.D. ${ }^{[b]}$ \\
\hline 2 & 3 & $\mathrm{CuBr}$ & $\mathrm{CH}_{3} \mathrm{OH}$ & N.D. ${ }^{[b]}$ \\
\hline 3 & 3 & Grubbs' 1st & $\mathrm{CH}_{3} \mathrm{OH}$ & N.D. ${ }^{[b]}$ \\
\hline 4 & 4 & none & $\mathrm{CH}_{3} \mathrm{OH}$ & 48 \\
\hline 5 & $5 \mathbf{a}$ & none & $\mathrm{CH}_{3} \mathrm{OH}$ & 81 \\
\hline 6 & 6 & none & $\mathrm{CH}_{3} \mathrm{OH}$ & 28 \\
\hline 7 & $5 \mathbf{a}$ & none & $\mathrm{CH}_{3} \mathrm{OH}$ & $71^{[\mathrm{c}]}$ \\
\hline 8 & $5 \mathbf{a}$ & none & toluene & 82 \\
\hline 9 & $5 \mathbf{a}$ & none & THF & 84 \\
\hline 10 & $5 \mathbf{a}$ & none & DMF & 79 \\
\hline 11 & $5 \mathbf{a}$ & none & $\mathrm{DMF} / \mathrm{H}_{2} \mathrm{O}$ & 71 \\
\hline
\end{tabular}

[a] Isolated yields [b] Not detected. [c] 1.0 equiv of TEMPO was added.

First, we screened the reaction conditions by using the glutamine-derived thioamide $\mathbf{1 a}$ as the substrate (Table 1 ). When the reaction was conducted in methanol at $0 \stackrel{\circ}{\circ}$, the addition of a metal catalyst, i.e., $\mathrm{Rh}_{2}(\mathrm{OAc})_{4}, \mathrm{CuBr}$, or Grubbs' first generation catalyst, with diazomalonate $\mathbf{3}$ as the metal carbenoid precursor, no reaction occurred (Table 1, entries 1-3). The use of iodonium ylide 4, with a methoxymethyl group at the ortho position, gave the desired enaminone $2 a$ in $48 \%$ yield (Table 1, entry 4). Finally, an ortho nitro-substituted iodonium ylide $5 \mathrm{a}$ was found to be the best reagent to furnish $2 \mathrm{a}$ in $81 \%$ yield (Table 1, entry 5). A significant drop in the yield and many unidentified byproducts were observed when the simple iodonium ylide 6 was used (Table 1, entry 6 ). These results strongly indicate the importance of ortho substitution of the aromatic ring of iodonium ylides. In this reaction, the addition of TEMPO as a radical scavenger did not significantly decrease the yield (Table 1 , entry 7 ), suggesting that a radical intermediate would not be involved in the reaction mechanism. The effect of the solvent was then studied (Table 1, entries 8-11). When nonpolar solvents such as toluene and THF were used, enaminone 2a was obtained in $82 \%$ and $84 \%$ yields, respectively (Table 1 , entries 8 and 9). Notably, aqueous media and DMF, which are often used to dissolve complex molecules, gave the desired product in good yields (Table 1, entries 10 and 11).
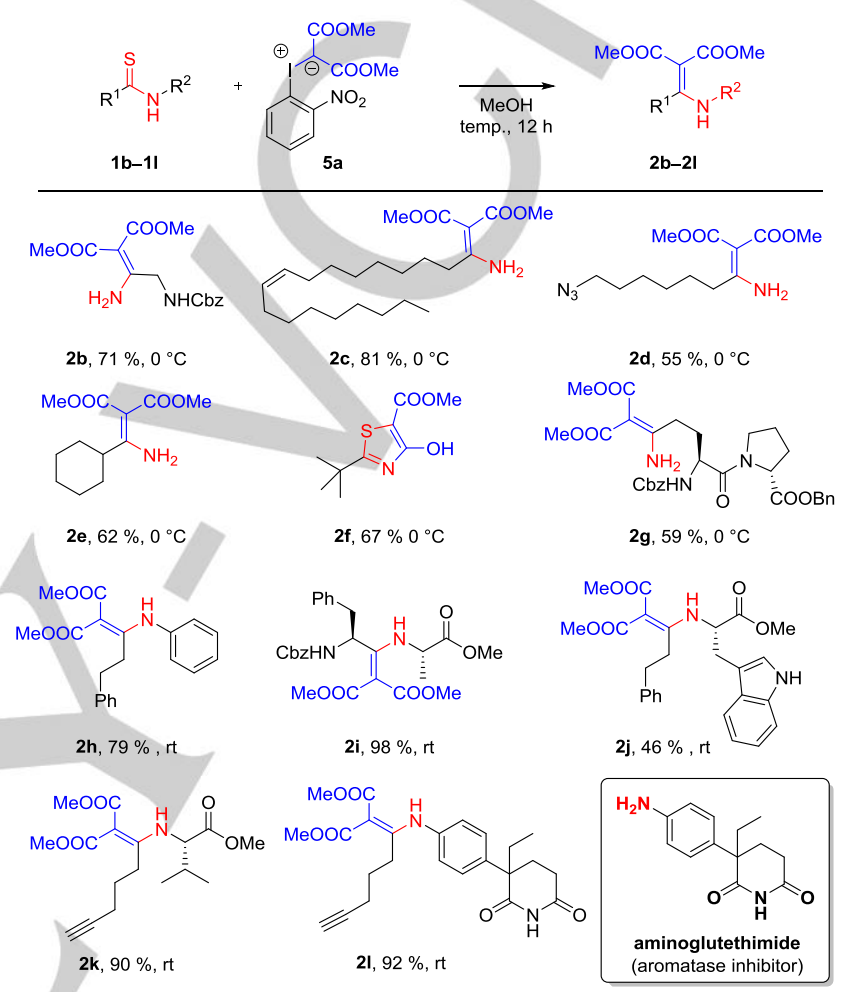

Figure 1. Substrate scope for synthesis of enaminones.

With the optimum reaction condition in hand, we investigated the substrate scope of the reaction between thioamides and a nitrosubstituted iodonium ylide (Figure 1). Various primary thioamides were tolerated in the reaction with iodonium ylides. Thioamides derived from glycinamide and oleamide gave enaminones in $71 \%$ and $81 \%$ yields, respectively (Figure 1, 2a, 2c). This reaction was also applicable to a substrate with an azide moiety (2d), which could potentially be used for further functionalization via nitrene insertion ${ }^{[19]}$ or click reactions ${ }^{[20]}$ in the presence of a metal catalyst. Although enaminone $2 \mathbf{e}$ was obtained from cyclohexanethiocarboamide in $62 \%$ yield, desulfurization did not occur when thiopivaloylamide was used, because of steric hindrance, and thiazole $\mathbf{2 f}$ was obtained in $67 \%$ yield. This reaction can also be conducted with the thioasparagine residue of a dipeptide $(\mathbf{2 g})$, indicating the potential of this method for late-stage functionalization of more complex peptides with thioamide moieties. This reaction was then applied to secondary thioamides. The desired enaminone was obtained in $79 \%$ yield from the simple thioanilide $\mathbf{2 h}$. The reactions with secondary thioamides were performed at room temperature. A substrate with thioamide moieties as the main 
peptide chain gave the target product $\mathbf{2} \mathbf{i}$ in $98 \%$ yield. Finally, this reaction was applied to the functionalization of pharmaceuticals. The thioamide derived from the aromatase inhibitor aminoglutethimide, ${ }^{[21]}$ which has been used as the second- or third-line choice in the treatment of hormonesensitive metastatic breast cancer, reacted with 5 a to give enaminone $2 \mathbf{l}$ in $92 \%$ yield. It is worth mentioning that the reaction proceeded even when alkyne functional groups were present, which could be further functionalized with azidecontaining probes or biomolecules through the orthogonal click reaction. ${ }^{20]}$

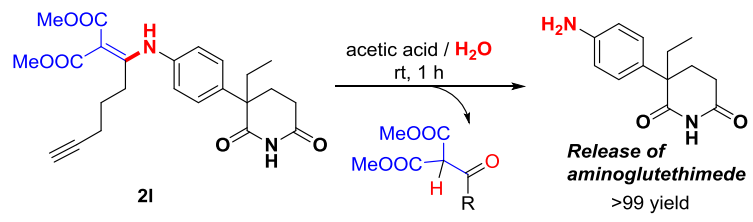

Scheme 2. Release of aminoglutethimide

To demonstrate the utility of this reaction, the selective cleavage of this enaminone moiety for the potential prodrug applications was investigated (Scheme 2). The reaction of enaminone 2l, which contained aminoglutethimide, in an acidic solvent released aminoglutethimide almost quantitatively. ${ }^{[6]}$ The poor pharmacokinetics of aminoglutethimide ${ }^{[21 b]}$ might be improved by functionalization based on this methodology.

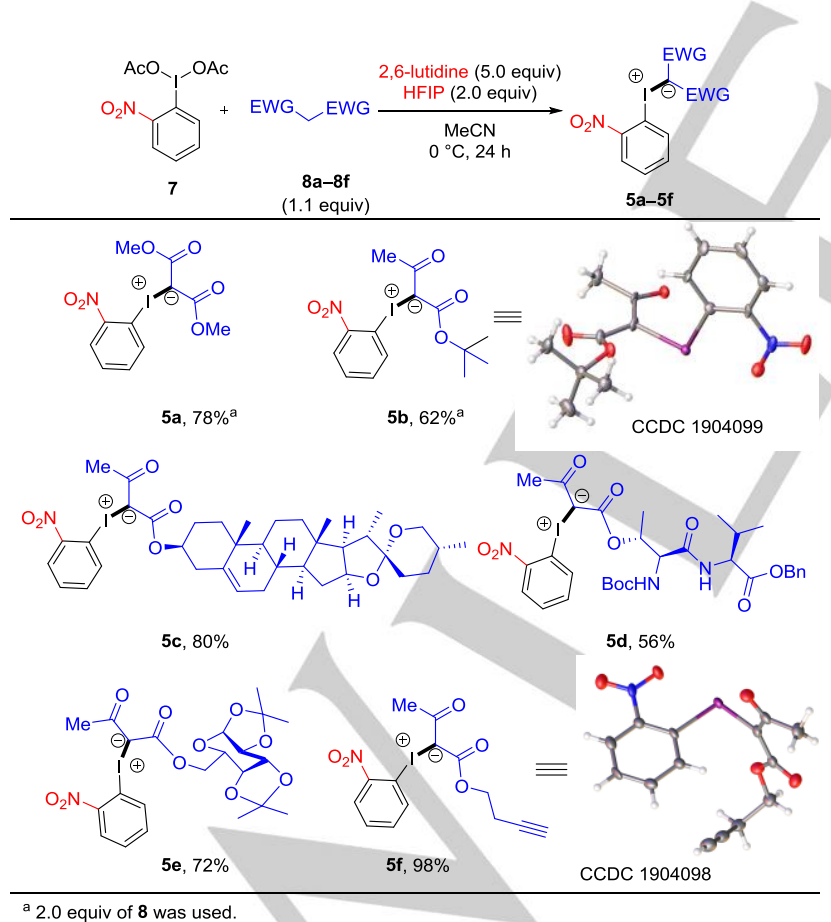

Figure 2. Substrate scope for synthesis of iodonium ylides

We next investigated the transformation of a $\beta$-ketoester-derived iodonium ylide to a thiazole by coupling with a thioamide (Figure
2,3). We envisioned that this thiazole synthesis could be used to link complex molecules via thiazole pharmacophores. This strategy requires the introduction of complex molecules into iodonium ylides. However, the conditions generally used to access iodonium ylides (e.g., use of $\mathrm{KOH}$ or $\mathrm{KOMe}$ in methanol or acetonitrile) would lead to decomposition or epimerization of complex molecules. After various screenings of solvents, bases, and additives, we identified the appropriate reaction conditions for the preparation of various iodonium ylides (Figure 2). A mixture of 2-iodobenzene diacetate $\mathbf{7}$, an active methylene compound 8 (1.1 or 2.0 equiv), 2,6-lutidine (5.0 equiv), and hexafluoro-2-propanol (HFIP) (2.0 equiv) in acetonitrile at $0 \stackrel{\circ}{ } \mathrm{C}$ gave the corresponding iodonium ylides in moderate to excellent yields. ${ }^{22]}$ This method gave the dimethyl malonate-derived iodonium ylide in $78 \%$ yield (Figure 2, 5a). As well as diestercontaining iodonium ylides, ketoester-containing iodonium ylides were synthesized. The product derived from tert-butyl acetoacetate was obtained in $62 \%$ yield $(\mathbf{5 b})$. Complex molecules such as diosgenin and dipeptides (5c and $\mathbf{5 d}$ ) were synthesized without any decomposition or epimerization, in $80 \%$ and $56 \%$ yields, respectively. These iodonium ylides were stable even when subjected to silica-gel column chromatography, presumably because of the ortho effect. lodonium ylides bearing a protected sugar moiety (5e) or an alkyne group (5f) were synthesized under these reaction conditions.

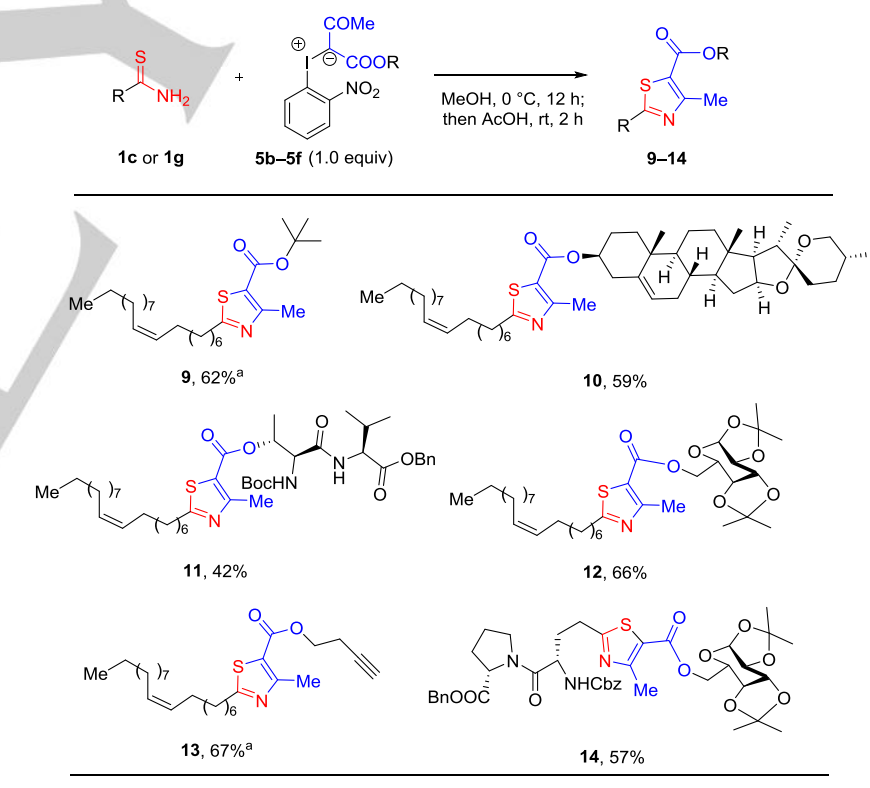

a 1.5 equiv of 5 was used.

Figure 3. Substrate scope for synthesis of thiazoles

We then investigated the reactions of the above prepared functionalized iodonium ylides $\mathbf{5 a}-\mathbf{f}$ with thioamides to give thiazoles (Figure 3 ). When the iodonium ylides were reacted with oleamide derivatives, the desired thiazole 9 was obtained in $62 \%$ yield, although the addition of acetic acid was required for dehydration. We then conducted the reaction with complex iodonium ylides $\mathbf{5 c - e}$, bearing diosgenin, dipeptide, and sugar moieties. These ylides were effectively converted to the 
corresponding thiazoles (10-12) in 59\%, 42\%, and 66\% yield, respectively. An alkyne group was also tolerated under the reaction conditions. Finally, we tried to use the reaction to introduce a sugar into a peptide. Iodonium ylide $5 \mathrm{e}$ reacted rapidly with the thioasparagine residue of a dipeptide to furnish the desired thiazole $\mathbf{1 4}$ in $57 \%$ yield. The introduction of the sugar moiety could improve the physical properties of the bioactive molecules, and this example showed the potential of this method for achieving conjugation of two complex molecules.
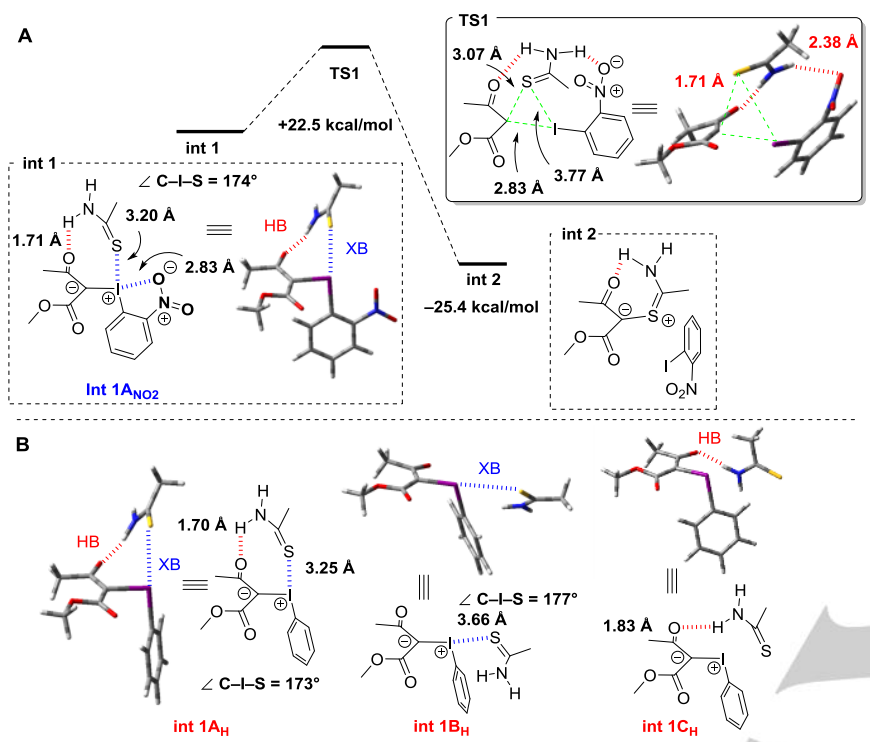

Figure 4. (A) transition state for $\mathrm{C}-\mathrm{S}$ bond formation and (B) complexation of iodonium ylides and thioamides

To gain the insight into the reaction mechanism, DFT calculations were performed with a thioacetamide and the iodonium ylide derived from methyl acetoacetate as model substrates, including the effects of ortho substituents on iodonium ylides (Figure 4). A three-atom-centered transition state $^{[13 a, b]}$ was proposed for $C-S$ bond formation (Figure $4 A$ ); the calculation was performed with Gaussian $09^{[23]}$ at the B97D/6$31 \mathrm{G}(\mathrm{d}, \mathrm{p})$ level $^{[24]}$ and the DGDZVP basis set ${ }^{[25]}$ was used for iodine. Regardless of the ortho substituent, the calculated activation energies for $\mathrm{C}-\mathrm{S}$ bond formation were ca. $20 \mathrm{kcal} / \mathrm{mol}$ in all cases (Figure S5, S6), ${ }^{[22]}$ suggesting that the ortho substituent on the iodonium ylide did not affect the activation energies. More importantly, the results suggest that both hydrogen bonding and halogen bonding promoted complexation of the thioamide and iodonium ylide to give the intermediate Int $\mathbf{1 A}_{\mathrm{NO} 2}$ before the $\mathrm{C}-\mathrm{S}$ bond-forming step. In the absence of an ortho substituent, several optimized structures were obtained, presumably because the halogen-bond-donating ylide $\sigma^{*}{ }_{C-1}$ orbital is readily accessible by the thioamide (Int $\mathbf{1 B}_{\mathrm{H}}$ ), and the aromatic ring of the iodonium ylide is sufficiently flexible for the thioamide to readily interact with the carbonyl moiety of the iodonium ylide through hydrogen bonding (Int $\mathbf{1 C}_{\mathbf{H}}$ ). These intermediates could lead to side reactions such as dimerization.
These results suggest that the ortho nitro substituent would control the coordination mode (Figure S1-S3), ${ }^{[22]}$ leading to selective formation of the desired $\mathrm{C}-\mathrm{S}$ bond rather than lowering the activation energy of $\mathrm{C}-\mathrm{S}$ bond formation.

In conclusion, we have developed a chemoselective reaction of thioamides with iodonium ylides. Halogen-bonding interactions between the species are responsible for the high chemoselectivity and wide functional group tolerance in polar solvents. In addition, the ortho substituent on the iodonium ylides can control the coordination mode of the nucleophile via $\sigma$-holes, suppressing undesired side reactions. These findings would enhance chemoselective coupling reactions using hypervalent iodine compounds. This improved method for iodonium ylide preparation will also enable the development and expansion of carbenoid chemistry. A detailed mechanistic study and investigation of applications of this reaction in bioconjugation are underway in our laboratory.

\section{Experimental Section}

To a solution of thioamide 1a $(17.6 \mathrm{mg}, 0.05 \mathrm{mmol})$ in $\mathrm{MeOH}(1.0 \mathrm{~mL})$ was added iodonium ylide $5 \mathrm{a}(28.4 \mathrm{mg}, 0.075 \mathrm{mmol})$ at the indicated temperature. After being stirred at the same temperature for 12 hours, the crude mixture was directly purified by preparative TLC (Eluent: $n$ hexane/EtOAc $=75 / 25)$ to give desired products $2 \mathrm{a}(18.2 \mathrm{mg}, 81 \%)$.

\section{Acknowledgements}

This work was partly supported by JSPS KAKENHI (grant numbers $16 \mathrm{H} 06384$ and 17K15423) and the Takeda Science Foundation. The molecular geometries for the transition states were first estimated with the Reaction plus software package, based on the nudged elastic band method, ${ }^{[26]}$ and were subsequently re-optimized using the Gaussian 09 software package.

Keywords: halogen bonding $•$ hypervalent compounds $\bullet$ thiazole - enaminone $\cdot$ chemoselective reaction

[1] a) J. H. Miwa, A. K. Patel, N. Vavatrat, S. M. Popek, A. M. Meyer, Org Lett. 2001, 3, 3373-3375. b) J. H. Miwa, L. Pallivathucal, S. Gowda, K. E. Lee, Org. Lett. 2002, 4, 4655-4657. c) A. Reiner, D. Wildemann, G. Fischer, T. Kiefhaber, J. Am. Chem. Soc. 2008, 130, 8079-8084. d) R. M. Culik, H. Jo, W. F. DeGrado, F. Gai, J. Am. Chem. Soc. 2012, 134, 8026-8029. e) R. W. Newberry, B. VanVeller, R. T. Reines, Chem. Commun. 2015, 51, 9624-9627. f) C. R. Walters, D. M. Szantai-Kis, Y. Zhang, Z. E. Reinert, S. Horne, D. M. Chenoweth, E. J. Petersson, Chem. Sci. 2017, 8, 2868-2877. g) X. Chen, E. G. Mietlicki-Baase, T. M. Barrett, L. E. McGrath, K. Koch-Laskowski, J. J. Ferrie, M. R. Hayes, E. J. Petersson, J. Am. Chem. Soc. 2017, 139, 16688-16695.

[2] a) For reviews on the synthesis of thioamide containing proteins, see: $Y$. J. Wang, M. Szantai-Kis, E. J. Petersson, Org. Biomol. Chem. 2015, 13, 5074-5081, and references cited therein. b) J. Yang, C. Wang, S. Xu, J. Zhao, Angew. Chem., Int. Ed. 2019, 58, 1382-1386. 
[3] T.S. Jagodziński, Chem. Rev. 2003, 103, 197-227, and references cited therein.

[4] E. M. Sletten, C. R. Bertozzi, Acc. Chem. Res. 2011, 9, 666-676, and references cited therein.

[5] a) X. Fontrodona, S. Díaz, A. Linden, J. M. Villalgordo, Synthesis 2001, 2021-2027. b) B. Shi, A. J. Blake, W. Lewis, I. B. Campbell, B. D Judkins, C. J. Moody, J. Org. Chem. 2010, 75, 152-161. c) M. A Honey, R. Pasceri, W. Lewis, C. J. Moody, J. Org. Chem. 2012, 77 1396-1405. d) N. D. K. Koduri, H. Scott, B. Hileman, J. D. Cox, M. Coffin, L. Glickberg, S. R. Hussaini, Org. Lett. 2012, 2, 440-443. e) N D. Koduri, Z. Wang, G. Cannell, G. Cooley, T. M. Lemma, K. Miao, M. Nguyen, B. Frohock, M. Castaneda, H. Scott, D. Albinescu, S. Hussaini, J. Org. Chem. 2014, 79, 7405-7414. f) A. Pal, S. R. Hussaini, ACS Omega 2019, 4, 269-280.

[6] G. Sauvé, N. L. Berre, B. Zacharie, Tetrahedron Lett. 1988, 29, 22992302.

[7] Z. Jin, Nat. Prod. Rep. 2013, 30, 869-915, and references cited therein

[8] D. Gillingham, N. Fei, Chem. Soc. Rev. 2013, 42, 4918-4931, and references cited therein.

[9] a) P. Müller, Acc. Chem. Res. 2004, 37, 243-251. b) M. S. Yusubov, A Yoshimura, V. V. Zhdankin, ARKIVOC, 2016, (i), 342-374.

[10] a) F. Heinen, E. Engelage, A. Dreger, R. Weiss, S. M. Huber, Angew. Chem. Int. Ed. 2018, 57, 3830-3833. For recent examples on the Lewis acidity of hypervalent iodines, see: b) A. Labattut, P. -L. Tremblay, O Moutounet, C. Y. Legault, J. Org. Chem. 2017, 82, 11891-11896. c) B Ye, J. Zhao, K. Zhao, J. M. McKenna, F. D. Toste, J. Am. Chem. Soc 2018, 140, 8350-8356. d) B. Zhou, M. K. Haj, E. N. Jacobsen, K. N Houk, X. -S. Xue, J. Am. Chem. Soc. 2018, 140, 15206-15218. For recent reviews, see: e) A. Yoshimura, V. V. Zhdankin, Chem. Rev. 2016, 116, 3328-3435. f) Hypervalent lodine Chemistry; T. Wirth, Ed. Springer-Verlag: Berlin, 2016

[11] For selected recent reviews, see: a) T. M. Beale, M. G. Chudzinski, M. G. Sarwar, M. S. Taylor, Chem. Soc. Rev. 2013, 42, 1667-1680. b) G. Cavallo, P. Metrangolo, R. Milani, T. Pilati, A. Priimagi, G. Resnati, G. Terraneo, Chem. Rev. 2016, 116, 2478-2601. c) D. Bulfield, S. M. Huber, Chem. Eur. J. 2016, 22, 14434-14450.

[12] For selected recent examples, see: a) F. Kniep, S. H. Jungbauer, Q. Zhang, S. M. Walter, S. Schindler, I. Schnapperelle, E. Herdtweck, S. M. Huber, Angew. Chem., Int. Ed. 2013, 52, 7028-7032. b) Y. Takeda, D. Hisakuni, C.-H. Lin, S. Minakata, Org. Lett. 2015, 17, 318-321. c) A Matsuzawa, S. Takeuchi, K. Sugita, Chem. Asian J. 2016, 11, 28632866. d) Y. -C. Chan, Y. -Y. Yeung, Angew. Chem., Int. Ed. 2018, 57 3483-3487. e) Y. Kobayashi, Y. Nakatsuji, S. Li, S. Tsuzuki, Y. Takemoto, Angew. Chem., Int. Ed. 2018, 57, 3646-3650. f) K. Matsuzaki, H. Uno, E. Tokunaga, N. Shibata, ACS Catal. 2018, 8, 6601-6605. g) T. Arai, S. Kuwano, T. Suzuki, Heterocycles 2018, 97, 163-169.

[13] a) R. Frei, M. D. Wodrich, D. P. Hari, P.-A. Borin, C. Chauvier, J. Waser, J. Am. Chem. Soc. 2014, 136, 16563-16573. b) D. P. Hari, P. Caramenti, J. Waser, Acc. Chem. Res. 2018, 51, 3212-3225. c) M. T. Taylor, J. E. Nelson, M. G. Suero, M. J. Gaunt, Nature 2018, 562, 563568.

[14] a) S. Telu, S. Durmus, G. F. Koser, Tetrahedron Lett. 2007, 48, 1863 1866. b) C. Zhu, A. Yoshimura, L. Ji, Y. Wei, V. N. Nemykin, V. V. Zhdankin, Org. Lett. 2012, 14, 3170-3173. c) M. Saito, Y. Kobayashi, S Tsuzuki, Y. Takemoto, Angew. Chem., Int. Ed. 2017, 56, 7653-7657.

[15] a) M. B. Camacho, A. E. Clark, T. A. Liebrecht, J. P. DeLuca, J. Am Chem. Soc. 2000, 122, 5210-5211. b) J. Guo, Y. Liu, X. Li, L. Liu, X Feng, Chem. Sci. 2016, 7, 2717-2721.

[16] S. R. Goudreau, D. Marcoux, A. B. Charette, J. Org. Chem. 2009, 74, 470-473.

[17] For pioneering work, see: a) C. Zhu, A. Yoshimura, P. Solntsev, L. Ji, Y Wei, V. N. Nemykin, V. V. Zhdankin, Chem. Commun. 2012, 48, 10108-10110. For selected recent examples, see: b) G. C. Geary, E. G. Hope, K. Singh, A. M. Stuart, RSC Adv., 2015, 5, 16501-16506. c) L. Wang, O. Jacobson, D. Avdic, B. H. Rotstein, I. D. Weiss, L. Collier, X.
Chen, N. Vasdev, S. H. Liang, Angew. Chem., Int. Ed. 2015, 54 12777-12781. d) B. H. Rotstein, L. Wang, R. Y. Liu, J. Patteson, E. E. Kwan, N Vasdev, S. H. Liang, Chem. Sci. 2016, 7, 4407-4417.

[18] For a recent review, see: a) V. V. Zhdankin, J. D. Protasiewicz, Coord. Chem. Rev. 2014, 275, 54-62. For our contributions, see: b) Y. Kobayashi, S. Masakado, Y. Takemoto, Angew. Chem., Int. Ed. 2018 57, 693-697. c) S. Masakado, Y. Kobayashi, Y. Takemoto, Chem. Pharm. Bull. 2018, 66, 688-690.

[19] For a recent review, see: R. A. Eikey, M. M. Abu-Omar, Coord. Chem. Rev. 2003, 243, 83-124

[20] For a review, see H. C. Kolb, M. G. Finn, K. B. Sharpless, Angew. Chem., Int. Ed. 2001, 40, 2004-2021.

[21] a) B. A. Gross, S. A. Mindea, A. J. Pick, J. P. Chendler, H. H. Batjer, Neurosurg. Focus 2007, 23, E10, and references cited therein. b) C. K. Osborne, Endocrime Therapies in Breast and Prostate Cancer, Kluwer Academic Publishers: Boston, 1988.

[22] See the Supporting Information for details

[23] M. J. Frisch, G. W. Trucks, H. B. Schlegel, G. E. Scuseria, M. A. Robb J. R. Cheeseman, G. Scalmani, V. Barone, B. Mennucci, G. A. Petersson, H. Nakatsuji, M. Caricato, X. Li, H. P. Hratchian, A. F. Izmaylov, J. Bloino, G. Zheng, J. L. Sonnenberg, H. Hada, M. Ehara, K. Toyota, R. Fukuda, J. Hasegawa, M. Ishida, T. Nakajima, Y. Honda, O. Kitao, H. Nakai, T. Vreven, J. A. Montgomery, Jr., J. E. Peralta, F. Ogliaro, M. Bearpark, J. J. Heyd, E. Brothers, K. N. Kudin, V. N. Staroverov, T. Keith, R. Kobayashi, J. Normand, K. Raghavachari, A. Rendell, J. C. Burant, S. S. lyengar, J. Tomasi, M. Cossi, N. Rega, J. M. Millam, M. Klene, J. E. Knox, J. B. Cross, V. Bakken, C. Adamo, J. Jaramillo, R. Gomperts, R. E. Stratmann, O. Yazyev, A. J. Austin, R. Cammi, C. Pomelli, J. W. Ochterski, R. L. Martin, K. Morokuma, V. G. Zakrzewski, G. A. Voth, P. Salvador, J. J. Dannenberg, S. Dapprich, A. D. Daniels, O, Farkas, J. B. Foresman, J. V. Ortiz, J. Cioslowski, D. J Fox, Gaussian 09, Revision D.01. Gaussian, Inc.: Wallingford, CT, 2009.

[24] S. Grimme, J. Comp. Chem. 2006, 27, 1787-1799.

[25] N. Godbout, D. R. Salahub, J. Andzelm, E. Wimmer, Can. J. Chem. 1992, 70, 560-571.

[26] G. Henkelman, H. Jónsson, J. Chem. Phys. 2000, 113, 9978-9985. 


\section{COMMUNICATION}

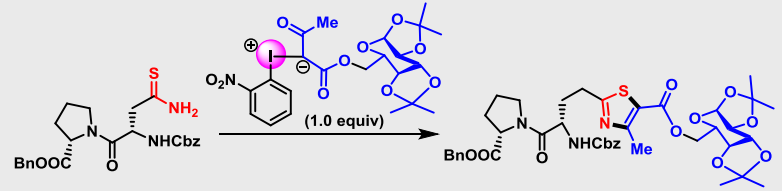

- Mild conditions - Highly chemoselective - Protic solvent available - A variety of iodonium ylides can be readily prepared

The reactions of thioamides with ortho-nitro-substituted iodonium ylides proceeded under mild conditions to give enaminones or thiazoles. This protocol allowed the use of protic solvents, including aqueous solutions, and therefore coupling reactions with complex molecules were possible. A mild and efficient method for the synthesis of various iodonium ylides was also established.
Masato Saito, Yusuke Kobayashi, Yoshiji Takemoto*

Page No. - Page No.

Divergent and chemoselective transformations of thioamides with designed carbene equivalents 